Portland State University

PDXScholar

$1-1-1982$

\title{
The Effect of Parent-Child Interaction on the Language Development of the Hearing-Impaired Child
}

Arla J. Melum

Portland State University

Follow this and additional works at: https://pdxscholar.library.pdx.edu/open_access_etds

Part of the Speech and Hearing Science Commons, and the Speech Pathology and Audiology Commons

Let us know how access to this document benefits you.

\section{Recommended Citation}

Melum, Arla J., "The Effect of Parent-Child Interaction on the Language Development of the HearingImpaired Child" (1982). Dissertations and Theses. Paper 70.

https://doi.org/10.15760/etd.70

This Thesis is brought to you for free and open access. It has been accepted for inclusion in Dissertations and Theses by an authorized administrator of PDXScholar. Please contact us if we can make this document more accessible: pdxscholar@pdx.edu. 
THE EFFECT OF PARENT-CHILD INTERACTION

ON THE LANGUAGE DEVELOPMENT OF THE HEARING-IMPAIRED CHILD

\author{
by \\ Arla J. Nielum
}

A paper submitted in partial fulfillment of the requirements for the degree of

\author{
MASTER OF SCIENCE \\ in \\ SPEECH COMMUNICATION \\ with emphasis in Audiology \\ and Speech Pathology
}

Portland State University

1982 
TABLE OF CONTENTS

PAGE

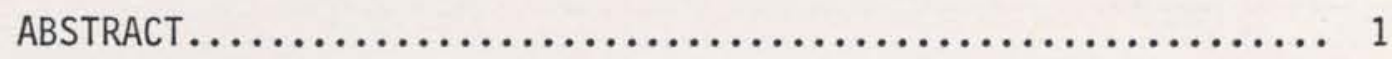

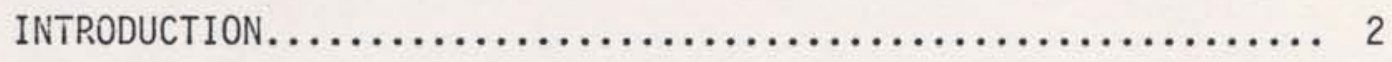

DISCUSSION......................................... 6

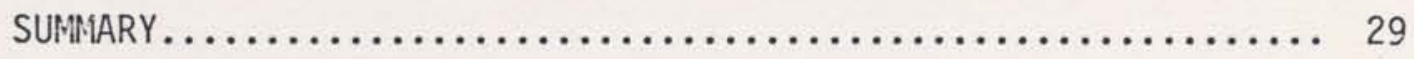

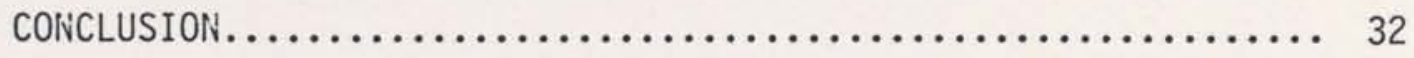

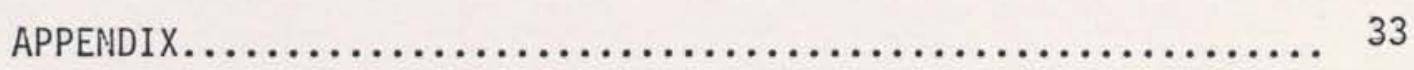

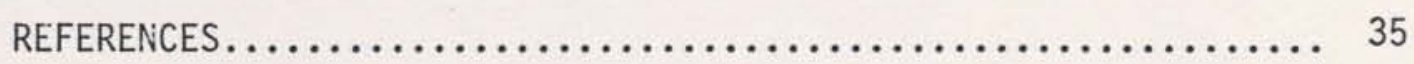




\section{ABSTRACT}

In recent years much interest has been focused on the manner in which the young child acquires language. Some researchers (Chomsky, 1965; McNeil, 1970) have postulated an inherent capacity to comprehend and utilize linguistic structures, while others such as Irwin, (1960), Hess and Shipman, (1965), and Greenstein, et al, (1974) have focused on experiential determinants of language competence in early childhood.

As with all children, the social and emotional behavior of deaf children is greatly influenced by their ability to communicate with significant others. Interactions between the normally developing child and his parents are characterized by mutual responsiveness, where each initiates and reciprocates communication. When a child's language development is delayed or impaired (as with a hearing loss), this communication process may also become impaired, with parents being unable to respond appropriately to confused or reduced messages from the child.

This paper reviews some of the pertinent research regarding the behavioral interaction between the parent and child and its effect on communication and psychosocial development. The implications of this data for the hearing-impaired child and his family are considered. It wi11 address the question, "What is it that parents with young hearingimpaired children do that facilitates or impedes speech and language development?" A methodology is also presented for developing effective communication between such children and their parents. 


\section{INTRODUCTION}

Surprisingly little use has been made of the hearing-impaired infant as a source of invaluable information regarding speech and language acquisition processes. In part, this under-utilization may be attributed to the limited availability of such populations for study. More relevant, perhaps, has been a lack of awareness of the extent to which advances in hearing aid technology and educational practices have permitted the acquisition of "natural" speech and language by the profoundly deaf child (Greenstein, et al, 1974). The variation in linguistic competence within the deaf population far exceeds that among the normally hearing, and the determinants of this enormous variation are largely unknown (Pollack, 1970). To attribute it to differences in innate intellectual or language gifts is to beg the question. It is often assumed that such variables as residual hearing capacity, method of training, age at which intervention is begun, and the degree of overall language input are critically relevant. However, little research has been done to separate out the contributions of each of these factors (Greenstein, et al, 1974).

A variable of crucial importance to the language acquisition of the young hearing-impaired child concerns the nature of the motherinfant interaction. In recent years, researchers are discovering what an active role even the youngest infant takes in the communication process, and that there must first be communication present before language can develop. During this early communication, both the infant and the parent have an effect on one another (Goldberg, 1977).

In the past it was felt that an infant was a passive participant 
in the communication process, that he was there to receive input from his caretaker so he could develop language in order to communicate. For many years it was believed that the infant began life as a passive "blob" confronted with the task of making sense out of sensory chaos (Greenstein, et al, 1974). A more recent view (Goldberg, 1977) considers the newborn infant to be active, capable of organizing complex information, and to be selectively attentive and capable of rapid learning. Upon careful examination, it appears the acceptance of the young infant as a competent though immature organism has been largely confined to the domain of perceptual and cognitive skills. When research on early social relations is considered, it is found that the "remarkable" perceptual and cognitive abilities of young infants is documented, while early social development continues to be studied under the "passive blob" model. Recognition of the infant as an active and competent contributor to the social relationships with caretakers has been late in coming, and is not yet widespread (Lewis and Rosenblum, 1974; Goldberg, 1977).

It is tremendously important to take a look at the parent-child relationship since it is out of this social interaction that communication grows. Goss (1970) stated that the most important phase of language development is brought about by socio-emotional interáction beginining once the child speaks his first word, and that most of the early interaction is between the child and his mother. From her the child acquires both a linguistic model that will last throughout his life and a value system by which he will be able to assess his experiences. Stayton, et al, (1971) elucidated further by saying that it is through this type of interaction that a child not only acquires a linguistic model, but 
also a value system, a feeling of lovability, and positive self-concept.

The quality of the parent-child relationship is even more critical for the deaf child who is deprived of an auditory stimulus and the social-emotional interaction conveyed by it (Goss, 1970). Much of the parent's affective meaning is lost to the child who is receiving only partial, if any, auditory information. Further, critical information relaying reassurance, feelings of love and tenderness, calmness and warning is also missed. Not only does the hearing-impaired child lose affective information, but he also may not learn speech and language incidentally (as does his hearing counterpart) until it is actively taught to him.

Clark and Watkins (1978) discussed the importance of considering a child as a dynamic partner in a two-way communication system, rather than as a language learner. The child has intentions to be expressed through a variety of means (gestures, facial expressions, signs, vocalizations), and if parents are sensitive to these expressed intentions and respond to them, the child will develop a communication system. According to Clark and Watkins, it was once believed that if language could be "poured" into the hearing-impaired child, he would automatically give it back. Thus, if the child could be taught language, then he could communicate. They stated that language does not necessarily lead to communication; communication must occur before language can develop. Communication is interaction when the child does something that elicits a response from the parent, or the parent does something that elicits a response from the child. This communication interaction ultimately leads to language acquisition.

Since parents are the primary teachers of their child, spending 
the majority of the child's waking hours with him, it is of crucial importance that the quality of their language is appropriate for stimulating language development (Goss, 1970; Seitz and Marcus, 1976). Therapists and teachers working with hearing-impaired children and their parents can teach these parents to not only evaluate, but to change the quality of the language they use with their child. These techniques may be a determining factor in the success of any habilitation program where establishing communication between the adult and the handicapped child is a major goal.

The following discussion will focus more specifically on how parent-child interaction affects communication development in the normally hearing child, and how the presence of a hearing loss influences it. In addition, a technique for teaching parents to be accurate observers of behavior and for evaluating their own language stimuli with the goal of improving behavior and increasing communication skills in their child is suggested. 


\section{DISCUSSION}

Studies of the language environment of the normally developing child have implications for providing appropriate language for hearingimpaired children. Several of these studies look closely at the way the parent and child interact soon after birth, and how this serves as a precursor to symbolic language (Snow, 1972; Nelson, 1973; Bateson, 1975; Seitz and Marcus, 1976; Clark and Watkins, 1978).

At birth the infant does not intentionally communicate ideas or feelings (Clark and Watkins, 1978). For example, when the baby cries, he is not intentionally announcing that he is hungry and wants to be fed. The cry is more of a reflexive act. It is part of the act of being hungry and not a separate communication behavior to announce hunger. According to Clark and Watkins, the child soon becomes aware that when he does cry, he receives attention and comfort from his parents. His cry has a definite effect on them, so he cries again to receive more comfort and satisfaction and soon it becomes a communicative act. Greenstein, et al, (1974) looked at the social interaction between the infant and his parents. They discovered that the parent reacts by smiling and talking to the infant as the baby smiles for comfort. When the baby realizes the smile has an effect, he continues, and at this point, communication has been initiated. Mehrabian (1968) called expressions from the child to elicit responses from other people in his environment "communicative intents." Other examples might include cooing, babbling, pointing, stretching, pulling, and grasping. These "communicative intents" discussed by Mehrabian can be perceived as negative or positive by the parent. Greenstein, et al, (1974) reported 
that babies whose mothers considered crying to be communication ("positive") versus irritation ("negative") seemed to have happier, better adjusted infants.

Parents also affect the child's behavior in a number of ways during the communication process. Clark and Watkins (1978) used the term "synchrony" to describe the way in which adult's speech affects the infant. Condon and Sander (1974) discovered that infants at age one to fourteen days synchronized their movements with the sound of adult speech. They felt that long before the infant begins to talk, he has already internalized the form and structure of the language system he will be learning to use. According to Todd (1968), a normal hearing child moves in rhythm to speech for several months after birth, and that the rhythm eventually becomes a part of him, i.e., it becomes "internalized." The rhythm and intonation of speech carries with it a great deal of the meaning about what is being said. Later on, the child will add words to the rhythm.

Brazelton, et al, (1974) observed interactions between mothers and their children and discovered that it is a two-way reciprocal process, with each participant taking a turn as the active and passive participant. One of the first examples of this kind of reciprocal interaction can be seen in feeding an infant. While the baby is feeding, the mother becomes quiet and inactive. She jiggles, strokes, and talks to the baby during pauses, and intervenes periodically. A mother reads the signals in her infant's behavior and then fits her own behavior into the temporal pattern he creates. Lewis and Friedle (1972) referred to this communication network as "the cradle of meaning." 
Schaffer (1977) states that from the beginning the infant's interaction with his mother assumes the form of a dialogue. At first the dialogue is basically one-sided: the mother must be paced by the infant and follow his lead. She waits for him to be silent, then fills in the pauses. However, their vocal exchanges seem like a conversation -- they take turns vocalizing. In this study, Schaffer found that the turn-taking pattern is just as well established in pre-verbal infants as in those who could sustain "real" conversations. The infants observed rarely vocalized simultaneously. When vocalization was simultaneous, it was usually during laughter or to indicate excitement. Schaffer determined that this lack of simultaneity was probably due to the fact that one cannot effectively talk and listen at the same time. Stern, et al, (1974) also studied mother-child communication and discovered that a child at this young age engages in social interaction, but that it helps the infant begin to understand the functions of language. In addition, she felt that these early "conversations" help the infant learn the culturally-acquired aspects of the language, such as initiation and termination of conversation, alternating between speakers, interrupting, and interspersing verbal and non-verbal elements.

Brazelton, et al, (1974) found the interaction between mothers and infants to be a kind of cyclical process in which both the child and mother play specific roles. They found the infant's behavior in a typical interaction to be characterized by a variety of predictable behaviors: 
Infant Behaviors

1. Initiation: The infant begins to look at his mother with relaxed face, dull eyes, and slowly moving arms and legs. If the mother is looking away, the infant may turn away abruptly.

2. Orientation: The eyes and face brighten and the infant turns his body toward his mother.

3. State of Attention: The body extremities alternately reach forward and circle back. The baby alternately reaches out and waits to receive from his mother. His eyes dull, then brighten, and fleeting smiles, grimaces, and vocalizations are apparent.

4. Acceleration: The body's activity builds. There become fewer oscillations of attention and inattention. The child builds up to vocalization. If the mother talks too much, she will cut short this vocal interchange. The infant vocalizes more when the mother quiets.

5. Peak of Excitement: This is characterized by jerky, intense behavior. The infant tries to decrease tension by sucking on his hands, yawning, holding onto his hands, etc.

6. Deceleration: The bright look dims and the infant becomes more relaxed. His smiles fade. His vocalizing ceases or becomes decreased in pitch, intensity, or variability. The infant may continue to vocalize, but with a dull, monotonous "holding" quality.

7. Withdrawa1: The infant turns away while keeping his mother in peripheral view. At that time, the process may began again.

Brazelton, et al, (1974) also studied the mother's behavior in

an interaction of this type. They believed that the parent typically exhibits a sequence of behavior based on the interchange with the infant:

Parent Behaviors:

1. The mother reduces interfering activity (feeding, changing, or soothing the infant if he becomes upset).

2. She sets the stage for a period of interaction (brings the baby within the line of vision). This is an alert 
rather than relaxed position.

3. She creates the desire for the child to interact (by her expressions, gestures, etc.).

4. The mother intensifies the infant's attention (increases her vocalizations and facial expression).

5. She shows sensitivity to the infant's signals for a need to recover from the intensity of the interaction. They found that if mothers allowed the child to do the cyclic turning away, it resulted in longer periods of attention from the infant when he turned back to her. Those who attempted to get the child's attention back immediately when he turned away found the baby was less responsive, and for shorter periods. The mothers must be sensitive to the baby's needs to use the looking-away behavior as a means of having some control over the amount of visual stimulation he can take during one of these intense interactions.

6. The mother allows for reciprocity, by giving the baby a "turn" to respond with his own behaviors. The infant is apt to vocalize less if the parent is constantly talking.

Ciark and Watkins (1978) also stressed the importance of turntaking in a parent-child interaction. They stated that mothers who communicate effectively with their children use turn-taking rather than a running monologue. They verbalize something, give their child an opportunity to respond, and assist the child with the response, if necessary. They considered turn-taking to be a five step process: Stages of Turn-Taking

1. The mother says something.

2. The mother gives the child a chance to respond (a "turn").

3. If there is no response, the mother may speak for the child.

4. If the child responds, his mother may imitate and expand the child's utterance (assist the child with the utterance).

5. The mother takes another turn. 
If a parent does not use this type of turn-taking, the child will not be likely to develop communication as quickly. If the parent is talking constantly, the child may turn away due to overstimulation (Clark and Watkins, 1978).

The infant is exposed to a number of sounds in his environment and must learn to make sense of them, as well as to determine which stimuli have the most importance to him (Clark and Watkins, 1978). Lewis, and Rosenblum (1974) stressed the vital role that parents play in helping the child learn to cue into one of the most important signals in the environment..- conversation directed to him. They observed that parents do this in a variety of ways, many of which are unconscious. Further, one of the ways in which parents cue the child that they are directing their speech to him is by talking in a way that is different from the way in which they talk to other adults or older children. According to Clark and Watkins (1978), this special way of talking to a child is termed "motherese." This term is utilized since the mother is the most important infant caregiver. However, it is also used by other family members, friends, and relatives who talk with the infant. Since "motherese" sounds different from adult speech, it helps to get the infant's attention, since he knows that someone is talking to him. It also maintains the infant's attention because it sounds novel and interesting. Clark and Watkins have listed the special features of "motherese":

Features of "Motherese"

1. The voice is higher in pitch than in adult conversation (falsetto).

2. Intonation is exaggerated. This may be the most important aspect of "motherese." 
3. Sentences are short and simple (those that are grammatically correct).

4. Few hesitations are noted within sentences or phrases, but longer than normal pauses are included between sentences or phrases (no fillers, like "err," "well," etc.).

5. Repetition is frequent.

6. Special words are included ("baby talk," "doggie," "kitty," etc.).

7. A high number of questions are utilized (as many as $50 \%$ of the mother's utterances to infants).

8. Mothers talk about the "here and now," (about what the child or parent is seeing or doing).

9. Non-verbal communication signals are used, such as gestures, facial expressions, and touching.

10. The speech is characterized by imitations, expansions, and prodding. "Imitation" refers to repeating what the child says. "Expansion" means providing a mature form of what the child is trying to say. "Prodding" is encouraging the child to finish a sentence.

In addition to the use of turn-taking and "motherese," parents use reinforcement as a means of establishing communication with their young children. Clark and watkins (1978) defined reinforcement as "rewarding the child for his communication attempts." This is an important aspect of the parent-child relationship. If the child is reinforced for his communication attempts, whether verbal or non-verbal, he is more likely to want to communicate again. Therefore, communication will develop allowing for language to recur at a later time.

Brazelton, et a1, (1974) determined what kinds of reinforcement are most effective in increasing the vocalizations of infants. The research indicated that an excellent reinforcer of infant babbling is the human voice. However, an even more effective reinforcer of a child's vocalizations is voice combined with human presence (the 
mother's looking at the baby and vocalizing simultaneously, for example). Clark and Watkins (1978) noted several behaviors exhibited by parents which seemed to be important to the reinforcement of their child's vocalizations. They included waiting until the child is finished babbling before imitating him, looking directly at the child when directing conversation to him, maintaining a distance of between seven to eight inches and three feet, and reinforcing vocalizations immediately following their occurrence.

Stern (1974) found that the mother's gazing behavior with her infant is also different than average adult gaze exchanges. He stated that mutual gaze between mother and infant often lasts over thirty seconds, which rarely occurs between adults other than lovers or people preparing to fight in our culture. This prolonged gazing tendency must also serve as a means by which the mother can get the child's attention. Stern suggested that the mother is less likely to look away if the infant is looking at her, and the infant is also less likely to look away if the mother is looking at him. This is the reciprocity factor alluded to earlier.

Normally developing children provide parents with very consistent cues to their cognitive development, since their age, size, language, and cognitive skills develop at a predictable rate (Seitz and Marcus, 1976). A common finding in the research has been that mothers alter the complexity of their language to young children, e.g., the mean length of utterance increases systematically with that of the child (Bloom, 1970; Stern, 1974; Seitz and Marcus, 1976). As the child's language increases in linguistic competence, the language addressed to him by the parent becomes more adult-like (Snow, 1972; Phillips, 1973). 
The adult tends to utilize slower speech with more pauses interjected as well as much simpler syntax and restricted vocabulary with the younger child. More redundancy is provided than in "normal" speech (Broen, 1972; Seitz and Marcus, 1976).

As a result of their studies with young children, Seitz and Riede11 (1974) and Seitz and Marcus (1976) determined that some child cues or characteristics govern the complexity of maternal language, although the nature of the characteristic is not clear. These researchers found that mothers: are especially sensitive to child language tied to their own language, i.e., imitation of the mother's language and the child's response to the mother's "wh" questions. Mothers may also gauge the child's competence by his age, size, or the kinds of activities around which mother-child communications revolve.

Children talk about what they do. Nelson (1973) has shown that the choice of words is personal and selective and that children tend to learn names of objects upon which they can act. The manner in which parents react to the child's early productions has consequences for subsequent language acquisition. For each child-produced word, parents provide or fail to provide feedback, indicating acceptance or rejection. The more tolerant of deviations, the more positive feedback the child receives. This positive feedback is conducive to the rapid acquisition of new words. Nelson continued by saying that language is acquired within this communication network as the infant or young child relates acoustic signals to events, objects, and relationships he experiences. Thus, determining appropriate language imposes consideration of the quality of mother-child communications. 
The manner in which the mother responds to her child is affected by the way in which the child responds to his mother and vice versa.

The previously cited research dealt primarily with the interaction between the parent and child when no handicapping conditions were present in the youngster. However, these studies have implications for the consideration of children whose speech and language may not be developing at a normal rate due to the presence of a hearing loss, retardation, or other conditions where sensory input may be partially or totally absent or confused (Marshall, 1973). A systematic analysis of verbal interactions between these children and their parents has the potential for providing a base from which habilitative measures may be developed.

The following studies show how the quality of the parent-child interaction is affected when input is reduced in the child. Even though hearing-impaired children are given primary consideration in this paper, some research is presented on children with delayed speech and language development and behavior problems due to other etiologies since the effects on the parent-child interaction are similar.

A sample of twenty mentally retarded children and their mothers and twenty non-retarded children and their mothers between the ages of three to five years was contrasted on the frequency of four verbal operants (Marshall, et al, 1973). These operants were classified into four categories: manding verbal behavior (demanding, commanding, requesting, and asking); a tact (naming, labeling, or describing as a verbal response to a stimulus); intraverbal responses (under the control of verbal stimuli, but having no point-to-point correspondence with them); echoic responses (the repetition of a response that has 
been made by another person). The verbal operants were obtained from a tape recorded fifteen minute play session involving each mother and her child. It was determined that non-retarded children and retarded children differed quantitatively with regard to verbal operants. Tacts, mands, and intraverbals occurred with greater frequency with the nonretarded children. The only difference between mothers was a higher mand rate for mothers of retarded children. Marshall, et al, (1973) concluded that the high frequency of mands emitted by the mothers of the retarded children could be due to a number of reasons:

a) With increased physical capability and decreased mental ability, the socialization of the retarded child may be limited, requiring a great deal of external control by the parent. The pattern of control emitted by the parent would be via mands that would generalize over a long time period to play situations.

b) The verbal expressive deficit on the part of the child could extinguish the mother's use of tacts, intraverbals, and echoics, leaving her with one habitual response manding.

c) The mother's mands may be followed by motor performance by the child which reinforces manding behavior; the child may comply by acting rather than talking.

Seitz and Riedell (1974) reported results of an experimental language therapy program for a severely retarded four-year-old Hindu child and her parents. The treatment target was the parent-child interactions, which initially were extremely controlling. The parents used more commands and questions than other types of utterances. Immediate results of this study showed improvement in non-verbal child behaviors such as positively responding to parents (complying, attending to the parent, and interacting verbally) and engaging in independent play after these techniques were modelled and discussed for them. These parents viewed their child as more competent and were able to 
support independent play and reduce their physical contact and interruptive behavior. Improvement in the child's verbal behavior was reported in follow-ups at three months and again at one year. Seitz and Riedell concluded that the parent-child interaction constitutes the child's language environment, and that it is the quality of this environment that will most affect the verbal behavior of the slowly developing child. They also summarized by saying that retarded children provide impaired and confusing feedback to their parents, which produces parental uncertainty expressed by a high rate of inefficient commanding and intrusiveness. Reduced responsiveness from the child creates a situation where it becomes difficult for the parent to know when he/ she has provided language appropriate in complexity or content.

Seitz and irarcus (1976) studied a twenty-month-old rubella female with multi-handicapping conditions, including hearing loss. The child appeared indifferent to most sounds, and her behavior was marked by frequent, severe temper tantrums. The parents came to the clinic to obtain assistance in understanding the level of the child's functioning, and to learn some behavior management techniques. Seitz and Marcus obtained pre-intervention data through observation and videotaping of the mother playing with the child "as if at home" for a period of twenty minutes. Progress was monitored through similar videotapes collected in the clinic, at home, and upon discharge from the program. Mean length of utterance was determined and classified into categories of: questions, affirmatives and negatives, and statements (imperatives and declaratives). Parental behaviors were coded as: directives (commands and questions), positives (conversational comments and praise), negatives (physical or verbal abuse or criticism), 
and unrelated. Child behaviors were scored as: positive responses (verbal interaction, compliance, or attending to the mother), independent play, no response, and as negative responses (verbal or physical refusal to comply).

The pre-clinic tape in the Seitz and Marcus study (1976) showed the child frequently withdrawing from the mother, engaging in mostly negative behavior, and vocalizing the phoneme [A] primarily. They also found that the mother's language usage was heavily weighted with directives and typically lacked attempts to interpret the child's vocalizations and use of developmentally appropriate questions such as "What is this?" Her mean sentence length was appropriate.

Seitz and Marcus (1976) discussed a strategy that was utilized to insure the appropriateness of the language addressed to this hearingimpaired child. This involved teaching the parents to direct their communication to the child's activities and interests as do parents of normally developing children. While attending this twenty week program, the parent was trained by therapists to comment on activities the child initiated, rather than to direct the activities herself, making frequent descriptive comments and repeating and expanding the child's vocalizations.

By the third week of the Seitz and Marcus study (1976), the child was engaging in vocal play, at times echoing the therapist. The mother observed her child beginning to show response to sound. She practiced these behaviors rather than commanding the attention of the child. She tried to use her activities to intrigue the child, and as the child became more responsive, the mother felt increasingly successful. Data from the post-clinic videotape revealed that the child had 
achieved an expressive vocabulary of thirty phonemes. At that time there existed an absence of negative and unresponsive behavior and an increase in independent play, indicating a reduction in intrusion and a high level of positive responding to the child's play by the mother. The child exhibited an increase in smiling and positive affect directed toward the parent. Tantrums had been ignored, and were non-existent by the end of therapy. In summary, this study conducted by Seitz and Marcus was built on the normal mother-child communication process, and helped a mother and child establish an ability to respond positively to one another, thus laying the foundation for language development.

Findings of a study conducted at the Lexington School for the Deaf by Greenstein, et al, (1974) concur with the data presented by Seitz and Marcus (1976). In the Greenstein study, mother-infant communication and language acquisition in deaf infants was examined. They observed parental interactions with their children and recorded and tabulated the results. The child's reciprocal interactions were noted as part of a longitudinal study to age forty months of a group of thirty deaf children admitted to an auditory training program during the first two years of life. It was discovered by these researchers that the children with better language skills looked more at their mothers at age two, and the mothers were found to be less coercive and more accepting and sensitive to the child. The process of reciprocal mother-child influence was clearly demonstrated. The more often the child looked, smiled, or vocalized to his mother, the more affectionate and attached to the child she became and the more responsive she was to his distress and demands. 
Clinical experience with hearing-impaired infants at the Lexington Infant Center suggested that the hearing mother's discovery that her child is deaf has traumatic effects, providing conflicting feelings of rejection, guilt, and overprotection. During pregnancy, the parent fantasizes about what the child will be like. Daydreams in which the mother sees the baby as a child showing traits she recognizes -"wish fulfillment" -- may cause her to see the coming child as an idealization of herself. The discrepancy between these expectations, hopes, and wishes and the reality presented when the child is born with a hearing loss, causes emotional distress. This can result in an increase in critical and coercive behavior by mothers of deaf children (Greenstein, et al, 1974; Butani, 1979).

Goss (1970) found that mothers of deaf children, when compared to mothers of hearing children, were less likely to use verbal praise or language showing solidarity and agreement, and were more likely to show verbal antagonism, disagreement, and tension. Schlesinger and Meadow (1972) observed mother-child interaction and found the deaf children received lower ratings for compliance and pride in skill mastery than the hearing controls. This finding is consistent with the fact that mothers of the deaf children were less permissive and flexible and more didactic and intrusive than the mothers of the hearing children. Greenstein, et al, (1974) have attributed the differences to the desire of the mother to communicate, with the nature of the child's disability making communication difficult and frustrating.

In the Lexington study, Greenstein, et al, (1974) observed that the number of critical, inhibitory utterances and the use of coercive motivational techniques were highly correlated with low language ac- 
quisition. In a study of hearing mothers of four to seven-year-old children, Altman (1973) found the mothers of linguistically competent children to be more actively involved in their child's language development, to generate more verbal interaction, and to monitor their child's behavior with more feedback. Altman discovered further that these mothers placed more pressure on their child to perform, gave more positive reinforcement, exhibited more warmth and positive affect, gave less negative reinforcement, and were more child-centered than the mothers of the linguistically less competent children.

Earlier studies conducted by Vernon and Koh in 1970 and 1971 showed linguistic superiority in deaf children of deaf parents. They believed it was due to the less traumatic discovery of the hearing loss. In the Lexington study (1974), deaf mothers were rated as warmer and the flow of communication appeared easier. Children from deaf families tended to do better in ratings and tests of language competence, but children of hearing parents rated as warmer and more sensitive to their child tended to do as well. The data from this study suggests that the nature of the mother-infant interaction was more crucial than the mother's hearing status. Mothers of linguistically superior children looked, vocalized, and gestured more and touched, moved toward, and stayed close to their child less. Their children tended to move toward their mothers and look at them more. Greenstein, et al, (1974) hypothesized that the child who is conditioned to expect criticism, restraint, and disapproval from his mother tunes her out in a play situation by averting his gaze and thereby avoiding the expected "don't." Looking behavior was not only considered to be an index of closeness, but a major avenue through which language is acquired, 
especially until such time as the hearing-impaired child's residual hearing can be sufficiently mobilized by hearing aids and training.

Greenburg (1979) studied two groups of hearing mother-deaf child dyads; one group used oral communication only and the other used simultaneous or total communication (speech and sign language using English syntax). Each dyad was observed participating in a fiveminute instructional task (finding a specific toy in a room) and a fifteen-minute play/separation procedure. Communicative competence was measured, which assessed the degree to which both mother and child displayed mutual or reciprocal understanding of each other's requests, demands, and questions.

Greenburg (1979) found that the simultaneous communication dyads showed higher scores of rating of communication competence (reciprocal understanding) and positive social interactions than the oral dyads. Children utilizing simultaneous communication were more compliant, touched their mothers more, and averted their gaze less frequently. Greenburg reported that the mothers in these dyads laughed more often than those in the other group. The oral mothers communicated more than the simultaneous communication mothers, but showed more selfrepetition. If repetitive statements were excluded from the analysis, the difference between the two groups became non-significant. Greenburg (1979) concluded that because simultaneous communication is the natural method of communication for the deaf, it may lead to more positive social interaction, thus making it easier to learn communication skills.

A behavioral technique utilizing either audiotape or videotape replay to evaluate the content and sequence of events in therapy was 
developed by Boone and Prescott in 1972. Unlike many other evaluation tools relying on pre- and post-testing of clients, this system enables the educator or therapist to evaluate the extensive therapy process in between testing situations as well as his/her interaction with clients. A therapy-scoring instrument based on ten categories used with playback allows the professional to determine the number of events he/she contributes to the session as opposed to the number of events performed by the client. This technique shows the advantage of using quantitative techniques and videotape to analyze changes occurring or not occurring during therapy sessions. This technique proposed by Boone and Prescott provides one method that enables the therapist or educator to evaluate his/her own interaction with the client, as well as to provide a model for parents.

Educators and therapists working with handicapped children are faced with a dilemma. To some extent they must intrude to insure verbal input. On the other hand, excessive intrusion may result in complete withdrawal so that an emotional empasse becomes a prime concern in itself. In this approach, the issue is resolved by attaching language to child-initiated activities, thus capitalizing on the child's attention and motivation. Parents can be taught to respond positively to such activities, which change as a function of the situation and the child's growth and development, and training can generalize across time and to different settings (Seitz and Marcus, 1976).

The previously discussed research strongly supports the theory that the parent and child have a definite effect on each other's behavior. It also suggests that the hearing-impaired child with parents who respond to him in an accepting, non-coercive manner will have high- 
er language levels than the child whose parents do not. In addition, the relationship between parent and child will be much more warm and loving if the parent is positive and attempts to center language experiences around the child's interests whenever possible. Based on the rationale for the importance of examining parent-child interaction, a methodology is presented for identifying and changing, if necessary, the language the parent utilizes with his/her hearing-impaired child. Infant Hearing Resource, located in Portland, Oregon, is an agency involved in early identification of hearing loss and the habilitation of hearing-impaired infants (age 0-4) and their parents. The staff looks primarily at two aspects of the parent-child interaction: 1) psychological and 2) communication. They want to help both child and parent respond positively to one another, thus laying the foundation for language development. Since communication is essential to the quality of the relationship, they are teaching the parents how to communicate and give the child skills for using language to communicate. They have been looking at the quality of that communication as it reflects feelings and elicits certain behaviors in the child (Infant Hearing Resource, 1981).

The staff of Infant Hearing Resource (1981) has developed a technique which attempts to affect parent communication style called "Coding Language Interaction." This technique is based on the work of researchers like Goss (1970), Greenstein, et al, (1974), Schlesinger and Meadow (1974), Seitz and Marcus (1976), and Greenburg (1979) who have shown the tremendous impact that parent language has on subsequent language acquisition of the hearing-impaired child. Its utilization has implications for those dealing with communication disorders aside 
from those resulting from hearing loss.

Parents enrolled in the program at Infant Hearing Resource are taught techniques of interacting with their child during daily activities and during play that will enhance their relationship. By gearing their verbal stimuli toward descriptive language, they are indirectly becoming more accommodating and nurturing. In their play with their hearingimpaired child, the parents can learn to avoid coercive behaviors and to replace them with ones that permit play to be child-determined. They are seeing that play can be an avenue to improving parent-child interaction, enhancing the child's self-esteem and increasing his/her language and communication competency. Parents are learning nurturing ways of relating to their child at the same time they are learning to deal with hearing loss (Infant Hearing Resource, 1981).

Changing attitudes and feelings is the ultimate goal. Rather than working at the cause, the staff at Infant Hearing Resource attempts to identify the end behavior and change the words the parent uses. They employ a behavioral model, in other words. By changing the words, the attitudes and feelings will change. This has proved to be more effective than just dealing with attitudes and feelings alone through the incorporation of traditional counseling techniques. When the parent is utilizing descriptive language, he/she cannot be punitive, thus creating a more positive affect toward the child. The technique provides the parent with a specific and tangible tool to use with his/her child. As a result, the parent can go about the business of helping his/her child develop and increase auditory and communication behaviors (Infant Hearing Resource, 1981). 
Utilization of the "Coding Language Interaction" technique (Infant Hearing Resource, 1981) presupposes that the teacher or therapist has built a trust relationship with the parent already, having allowed him/her to know the professional as an individual. Due to an empathic understanding of the parent's feelings, the professional is in a position to help that person begin coping and to teach the skills he/she will need to use at home with the hearing-impaired child. The clinician or teacher and the parent, who are equal members of the habilitation process, are involved together every step of the way.

The technique developed at Infant Hearing Resource (1981) provides a simple, straightforward method by which an educator or therapist can evaluate and affect the parent-child interaction. The plan can be easily adapted to the specific needs and individual levels of skill and understanding of the parent, and does not require special equipment (other than a tape recorder or videotape system), evaluation tools, or extensive observation time. The "Coding Language Interaction" form (see Appendix A and B, page 33) has been developed by the staff of Infant Hearing Resource (1981) to facilitate the observation process. This writer has devised a suggested format for utilizing this technique with parents. This particular format has proved to be a successful one in changing parent's behavior (Melum, 1981):

1. Videotape or audiotape a short interaction (3-5 minutes) between the parent and child. Videotaping is preferable as it allows non-verbal communication to be observed in addition to verbal interchange. However, some parents might feel more comfortable and at ease if they knew they didn't have to "look good" for the camera. Instructions to the parent prior to this event might include something like "play with your child just as you would if you were at home." The goal here is to create as natural a play situation between the parent and child as possible, considering the contrived circumstances. 
2. Introduce the rationale for looking at parent-child interaction briefly to the parent. There is typically no need to delve more than generally into the research unless the parent is curious or asks for more information. The best selling device for this technique is the experience with it.

3. Introduce the categories that will be coded and agree on their meaning. Suggested definitions might include: "Descriptions" -- talking about what the child or parent is doing or seeing; "Commands" -- use of the imperative; telling the child to do something. An abbreviated tally sheet may be utilized with parents at the outset (see Appendix A, page 33). Later on, when the parents are more familiar with the categories and the coding process, you may add other headings such as "questions," "imitations/expansions of child's language," "praise," "affirmatives," and "negatives." The longer coding form would be utilized at this time (see Appendix B, page 34). Questions can be intrusive (test or command), a stimulant to cognitive development, an information request, or to elicit interaction, to reinforce, or to praise.

4. Show the parent a videotape (or let him/her listen to an audiotape) of a play interaction between a parent or teacher and a child. Both the teacher or therapist and the parent can code the language separately, then discuss it and compare data. The parent should be informed to make one tally mark for each of the adult's utterances under the appropriate category on the form. Keep practicing at this level until the parent appears to understand the concept.

5. Allow the parent an opportunity to code an interaction between the teacher or therapist and his/her child. Videotape or audiotape this segment, play it back, and code and discuss the interaction together.

6. Videotape or audiotape the parent playing with his/her own child. Ask him/her to code the language he/she used during this play segment. Discuss the results.

7. Provide positive reinforcement to the parent regarding any appropriate language he/she utilized with the child to help build confidence. Ultimately, the parent should provide most of the comments regarding his/her language with suggestions provided by the professional.

8. Re-evaluate periodically by retaping and allowing the parent many opportunities to code his/her language. Give the parent a chance to view or listen to the initial tape so he/she may code it and note improvement 
(or observe that using descriptive language has always been a strong point).

9. Consistently discuss with the parent that it is not the total number of tally marks under each category that is crucial, but the ratio of positive to negative aspects.

10. This suggested technique can be adapted in any way the educator or therapist feels is effective for the environment and population with which he/she works.

The teacher or therapist utilizing this technique will see an increase in descriptive language, praise and imitation and expansion of the child's language, and a decrease in intrusive language such as commands, questions, and negatives. Once the language behavior is altered, changes in affect will often be noticeable. Preliminary data gathered by this writer indicates that the child becomes more communicative, the parent feels better about his/her child, and the child feels reinforced by the parent. In general, the entire interaction becomes more positive (Melum, 1981). The parent will discover that he/she posesses the necessary resources for guiding the child's learning, instilling a feeling of confidence and competence in him/her. Most importantly, the parent can feel like he/she has the necessary skills to manage the child's hearing loss and to assist that child in achieving his/her maximum potential. 


\section{SUMMARY}

For many years it was believed that an infant was a passive participant in the communication process, that he was there to receive language input from his caretaker so he could develop language in order to communicate (Greenstein, et al, 1974). However, researchers are now discovering that the infant, even as a newborn, is capable of taking an active role in the communication process. Before language can develop, this communication between the infant and his caretaker must occur (Goldberg, 1977). It is important to consider the child as a dynamic partner in a two-way communication system, rather than as a language learner (Clark and Watkins, 1978). Most of the early interaction is between the child and his mother. From her he not only acquires a linguistic model, but also a value system, a feeling of lovability, and positive self-concept (Stayton, et al, 1971).

Brazelton, et al, (1974), Seitz and Marcus (1976), Schaffer (1977), and Clark and Watkins (1978) found the interaction between mothers and normally developing infants to be a kind of cyclical process in which both the child and mother play specific roles, whereby each takes turns initiating and responding to communication behaviors. Lewis and Rosenblum (1974) stressed the vital role that parents play in helping the child learn to cue into conversation directed to him, which is one of the most important environmental signals. Clark and Watkins (1978) stated that parents do this by talking in a way that is different from the way in which they talk to other adults or older children. This special way of talking is termed "motherese." According to Brazelton, et al, (1974) and Clark and Watkins (1978), one of the most 
important aspects of "motherese" is the reinforcement of the infant's vocalizations by the mother's presence, gaze, and imitation of these speech sounds. Studies of the language environment of the normally developing child, particularly those showing ways in which he/she learns best and most easily, have implications for children with language deficits due to hearing loss, retardation, etc. (Seitz and Marcus, 1976).

A hearing parent's discovery that his/her child is hearingimpaired has traumatic effects, producing conflicting feelings of rejection, guilt, and overprotection. The discrepancy between expectations, hopes, and wishes and the reality of having a hearing-impaired child causes emotional distress (Clark and Watkins, 1978; Butani, 1979). When a child's language development is impaired due to sensory deprivation, the communication process between the child and parent may also become impaired, with parents being unable to respond appropriately to confused or reduced messages from the child (Seitz and Riede11, 1974; Seitz and Marcus, 1976).

As a result of this impaired and confused feedback, parents often have a difficult time knowing when they have provided language appropriate in complexity or content. Parental uncertainty may be expressed by a high rate of commanding and intrusiveness (Goss, 1970; Altman, 1973; Seitz and Riede11, 1974; Greenstein, et a1, 1974; Seitz and Marcus, 1976). Studies have shown that parents of linguistically competent hearing-impaired children have typically been more actively involved in their child's language development than those of hearingimpaired children with lesser communication skills. These same parents also tend to generate more verbal interaction, to appear more sensitive 
and accepting of their child, to provide more positive reinforcement, to exhibit more warmth, and to seem more child-centered than the parents of linguistically less competent children.

Since parents are the primary teachers of the child, it is crucial that the quality of their language be appropriate for stimulating language development. Educators and therapists can assist the parent in learning ways to decrease the utilization of commands and questions with his/her child, and to increase the use of descriptive language centered around the child's interests. One way in which to accomplish this is to allow the parent an opportunity to code the language of other parents and professionals interacting with children, with the ultimate goal being to eventually have the parent evaluate his/her own language with his/her own child accurately. The "Coding Language Interaction" technique developed at Infant Hearing Resource (1981) has proved to be an effective method for accomplishing this goal. As a result of improved communication between the parent and child, the quality of the relationship is often enhanced. This technique proves invaluable in helping the parent and child feel more positive about one another, thus creating the optimal milieu in which to develop communication skills. 


\section{CONCLUSION}

This brief investigation reviews some of the pertinent research regarding the interaction between the parent and child and its profound effect on psychosocial and communication development. Several of the studies mentioned in this paper reveal how this crucial interchange is affected when the "normal" process of speech and language development is interrupted by the presence of a hearing loss. Many times the resulting cycle of parental frustration and negative child interaction creates a barrier that impedes the child's effective learning of communication skills.

Teachers and therapists who provide service to hearing-impaired children and their families are in an excellent position to deal with these emotional needs. Priority must be given to helping the parents adjust to their child's handicap, and to facilitating the flow of communication among them. This writer recommends the utilization of the "Coding Language Interaction" technique developed at Infant Hearing Resource to assist these parents in changing the type and quality of language they use with their hearing-impaired child. As a result, the professional should begin to see the parent-child interaction become more relaxed and "natural," resulting in increased communication. Consequently, the parents will develop a feeling of confidence and competence as managers of their child's education. 
APPENDIX A

\section{CODING LANGUAGE INTERACTION}

(Abbreviated form)

We will look at 2 types of communication, commands and descriptions.

We will describe a cormand as being directive, that is, telling the child what to do.

A description will be a statement (in your or your child's language) telling what you or your child is doing.

Examples of these are:

Command: "Do it this way," or "Put it in here."

Description: "You are pushing the wagon."

Let's chart how many commands or descriptions are used with the child.

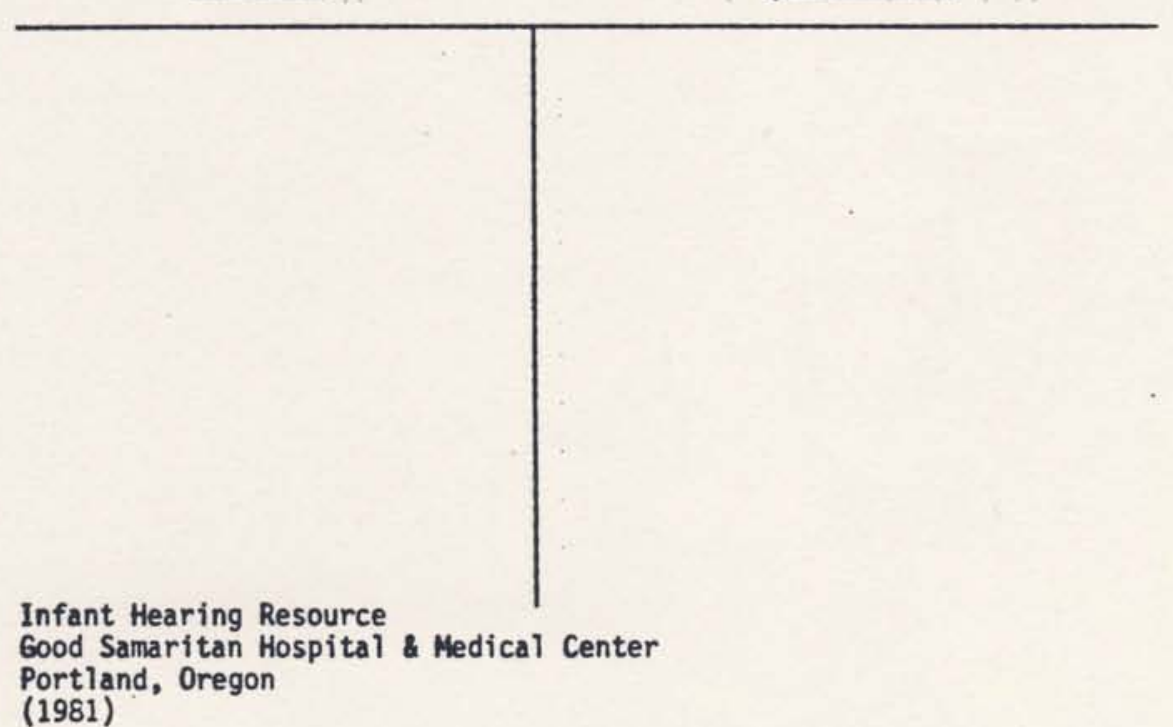


APPENDIX B

CODING LANGUAGE INTERACTION

Name of Observer(s)

Date

Person being observed

Child's Name

Categorize each observed utterance by providing a mark under the appropriate heading listed below:

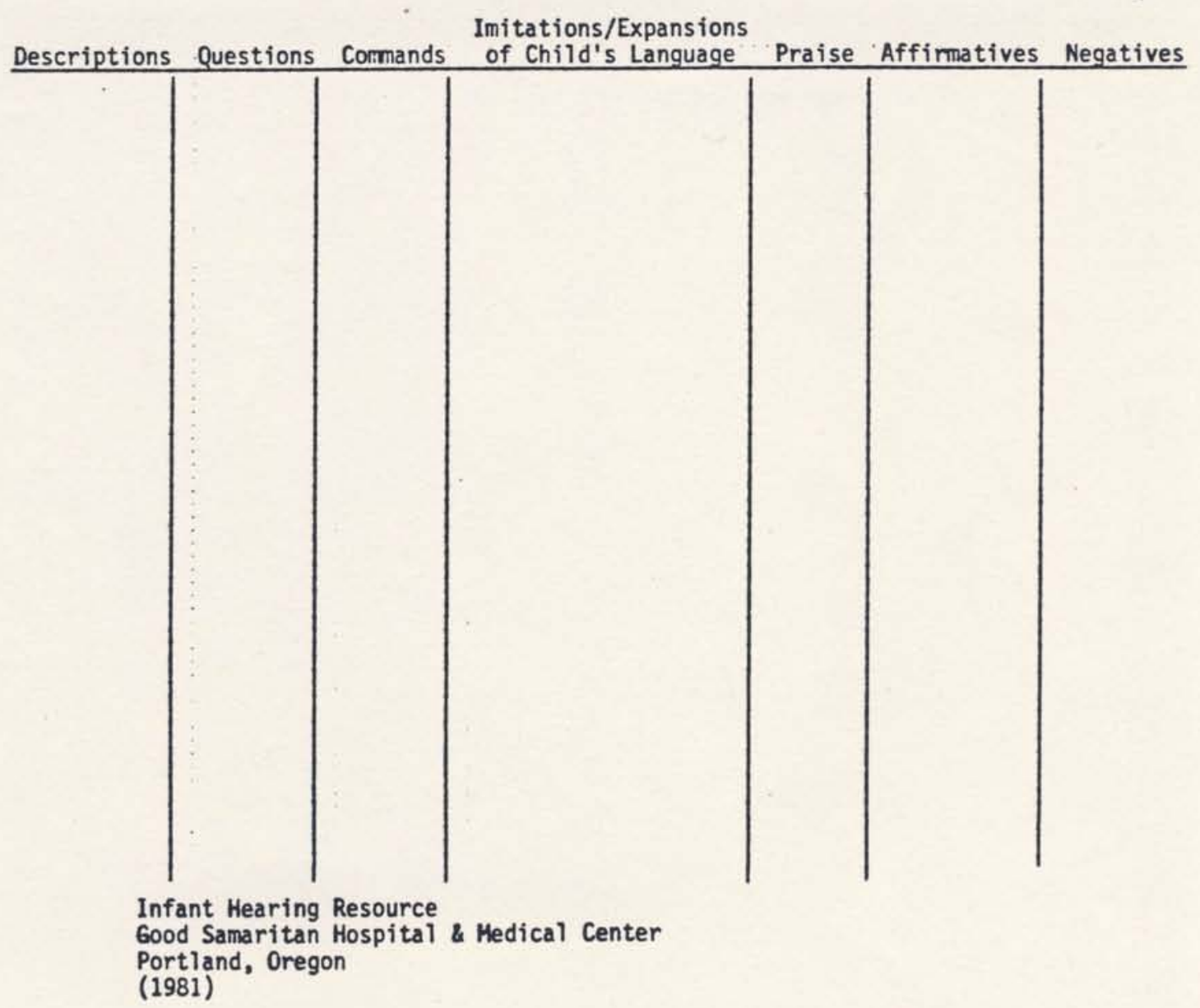




\section{REFERENCES}

Altman, E.D., "Some Factors in Mother-Child Interaction Related to Language Competence in Children with Severe Congenital Deafness." Paper presented at the Convention of the Eastern Psychological Association. Washington (1973).

Bateson, M., "Mother-Infant Exchanges: The Epigenesis of Conversational Interaction." Developmental Psycholinguistics and Communication Disorders, (1975).

Bloom, L.H., Language: Form and Function in Emerging Grammars. Cambridge: MIT Press (1970).

Boone, D. and Prescott, T., "Content and Sequence Analyses of Speech and Hearing Therapy." ASHA Journal, 14: 58-62 (1972).

Brazelton, T.B., B. Koslowski, and Main, M., "The Origins of Reciprocity: The Early Mother-Infant Interaction." In Lewis, M. and Rosenblum, L.A. (Eds.), The Effect of the Infant on Its Caregiver, New York: John WiTey and Sons (1974).

Broen, P.A., "The Verbal Environment of the Language Learning Child." ASHA Monograph, No. 17 (1972).

Butani, P., "Reactions of Mothers to the Birth of an Anomalous Infant: A Review of the Literature." Maternal-Child Nursing Journal, 111: 59-72 (1979).

Chomsky, N., Aspects of a Theory of Syntax. Cambridge: MIT Press (1965).

Clar, T., and Watkins, S., The SKI-HI Model: Programming for Hearing Impaired Infants Through Amplification and Home Intervention. U.S. Office of Education, Buraeau of Education of the Handicapped, Washington, D.C. (1978).

Condon, W.S. and Sander, L.W., "Neonate Movement is Synchronized with Adult Speech: Interactional Participation and Language Acquisition." Science, 183: 99-101 (1974).

Goldberg, S., "Social Competence in Infancy: A Model of Parent-Infant Interaction." Merrill-Palmer Quarterly, 23: 163-75 (1977).

Goss, R.N., "Language Used by Mothers of Deaf Children and Mothers of Hearing Children." Amer. Annals of the Deaf, 115: 93-6 (1970).

Greenburg, M.J. and Marvin, R.S., "Attachment Patterns in Profoundly Deaf Preschool Children." Merrill-Palmer Quarterly, 25: 265-79, (1972). 
Greenstein, J. and Greenstein, B. Bush, Mother-Infant Communication and Language Acquisition in Deaf Infants. Unpublished Study, Lexington School for the Deaf: New York (1974).

Hess, R.G. and Shipman, V.C., "Early Experience and the socialization of Cognitive Modes in Children." Child Development, 36: 869-86 (1965).

Irvin, 0.C., "Infant Speech: Effect of Systematic Reading of Stories." Journal of Speech and Hearing Research, 3: 187-90 (1960).

Lewis, M. and Friedle, R., Mother-Infant Dyad: The Cradle of Meaning. Princeton: EducationaT Testing Service (1972).

Lewis, M. and Rosenblum, L.A., The Effect of the Infant on Its Caregiver. New York: Wiley-Interscience (1974).

Marsha11, N., Hegrenes, J., and Goldstein, S., "Verbal Interaction: Mothers and Their Retarded Children vs. Mothers and Their Nonretarded Children." Amer. Journal of Mental Deficiency, 77: 415-19 (1973).

McNeil, D., The Acquisition of Language. New York: Harper and Row $(1970)$.

Hehrabian, A., "Communication Without Words." Psych. Today, Vol. II, 53-5 (1968).

Melum, A., "Coding Language Interaction: A suggested format." Infant Hearing Resource, Portland, Oregon (1981).

Melum, A., Rushmer, N., and Schuyler, V., "Coding Language Interaction," Infant Hearing Resource, Portland, Oregon (1981).

Nelson, K., "Structure and Strategy in Learning to Talk." Monogr. Soc. Res. Child Dev., 38: 149-54 (1973).

Phillips, J.R., "Syntax and Vocabulary of Mothers' Speech to Young Children -- Age and Sex Comparisons." Child Development, 44: 182-5 (1973).

Pollack, D., Educational Audiology for the Limited Hearing Infant. Springfield: Charles C. Thomas (1970).

Schaffer, R., Mothering. Cambridge: Harvard University Press (1977).

Schlesinger, H. and Meadow, K., Sound and Sign - Childhood Deafness and Mental Health, Los Angeles: University of California Press (1972).

Seitz, S. and Marcus, S., "Mother-Child Interactions: A Foundation for Language Development." Exceptional Children, 42(b): 445-9 (1976). 
Seitz, S. and Riedell, G., "Parent-Child Interaction as the Therapy Target." Journal of Comm. Disorders, 7: 295-304 (1974).

Snow, C., "Mothers Speech to Children Learning Language." Child Development, 43: 549-65 (1972).

Stayton, D.J., Hogan, R., and Ainsworth, M.D. Salter, "Infant Obedience and Maternal Behavior: The Origins of Socialization Reconsidered." Child Development, 42: 1057-69 (1971).

Stern, D.N., "Mother and Infant at Play: The Dyadic Interaction Involving Facial, Vocal, and Gaze Behaviors." In Lewis, M. and Rosenblum, L.A. (Eds) The Effect of the Infant on Its Caregiver. New York: John Wiley and Sons (1974).

Todd, G. and Palmer, G., "Social Reinforcement of Infant Babbling." Child Development, 39: 591-6 (1968).

Vernon, M. and Koh, S.D., "Early Manual Communication and Deaf Children's Achievement." Amer. Annals of the Deaf, 115: 527-36 (1970).

Vernon, M. and Koh, S.D., "Effects of Oral Preschool Compared to Early Manual Communication on Education and Communication in Deaf Children." Amer. Annals of the Deaf, 116: 569-74 (1971). 